\title{
Development the Scale of Ability of Preschool Teachers to Promote Children's Mathematical Thinking, and Situational Analysis of Japanese Preschool Teachers
}

\author{
Takeshi Sakai', Kohei Okado², Hideyuki Akai ${ }^{3}$ \\ ${ }^{1}$ Kyoto Women's University, Kyoto, Japan \\ ${ }^{2}$ Vories Gakuen Omi Brotherhood Junior High School, Shiga, Japan \\ ${ }^{3}$ Takeshirodai Elementary School in Sakai City, Osaka, Japan \\ Email: sakaita@kyoto-wu.ac.jp
}

How to cite this paper: Sakai, T., Okado, K., \& Akai, H. (2019). Development the Scale of Ability of Preschool Teachers to Promote Children's Mathematical Thinking, and Situational Analysis of Japanese Preschool Teachers. Psychology, 10, 1726-1741. https://doi.org/10.4236/psych.2019.1012113

Received: August 20, 2019

Accepted: September 23, 2019

Published: September 26, 2019

Copyright @ 2019 by author(s) and Scientific Research Publishing Inc. This work is licensed under the Creative Commons Attribution International License (CC BY 4.0).

http://creativecommons.org/licenses/by/4.0/

\begin{abstract}
This study developed the scale that assesses the ability of preschool teachers to promote children's mathematical thinking, and conducted the situational analysis of Japanese preschool teachers. The purpose of this study was to develop the scale of the ability about promoting children's mathematical thinking in preschool teachers and assess their ability. For that reason, a questionnaire was conducted to preschool teachers who were working in preschools $(\mathrm{N}=157)$ and, a survey of exploratory factor analysis was conducted, which extracted seven factors: "The ability to read the play that leads to Basis of Mathematics (extensions)", "Advice for leading to Basis of Mathematics", "The way of thinking to Basis of Mathematics", "Practice of childcare leading to Basis of Mathematics", "The ability to read the play that leads to Basis of Mathematics (basics)", "Understanding Basis of Mathematics", and "The way of thinking to preschool education". Then, the situational analysis was conducted. Results indicated the ability of preschool teachers to promote children's mathematical thinking in preschool teachers was not at enough level. Furthermore, the t-test conducted on the several experiences of preschool teachers and the seven factors was investigated. Results indicated that on the five factors the average values of teachers who had an experience of working in kindergarten were higher than that of teachers who had no experience of working kindergarten. These results suggest that developing the scale to assess the ability of preschool teachers in order to promote children's mathematical thinking is significant and by using this scale we become able to grasp the actual situation of the teachers and the important matter of teachers' education.
\end{abstract}




\section{Keywords}

Pre-School Education, Mathematical Thinking, The Ability of Preschool Teachers

\section{Introduction}

\subsection{Research Purpose}

Enhancement of science and mathematics education is required. A necessity of cultivating the basis of mathematics is increasing more and more. It is also necessary for preschool teachers to change their consciousness toward mathematics in early childhood education and to construct the play that leads to Basis of Mathematics. Especially mathematical thinking is important as Basis of Mathematics. But ability of preschool teachers to promote children's mathematical thinking isn't clarified and a scale to measure the ability isn't developed.

The purpose of this study is to develop a scale for assessing preschool teachers' ability in order to promote the early development of children's mathematical thinking. This scale makes it possible to analyze the current situation of the preschool teachers for mathematics education in early childhood education.

\subsection{Mathematics Education in Early Childhood Education}

The mathematics education in early childhood education has changed significantly in recent years. Basic developmental research conducted over the past 25 years has fundamentally changed the way in which the early development of mathematical thinking is understood (Starkey et al., 2004). In the past, preschoolers were thought to have no mathematical knowledge because they could not use abstract numerical notation, such as written numerals or operation signs. For this reason, traditional learning theorists argued that the development of children's mathematical knowledge began with the formal schooling of mathematics from elementary school (Bereiter \& Engelman, 1966). Piaget (1952) shifted the focus of research on the development of mathematical knowledge before formal schooling of mathematics. Piaget and Following researchers did not use abstract numerical notation to measure mathematical knowledge (Starkey et al., 2004). This has made it possible to measure the effect of early childhood education on mathematics education, and to draw attention to its importance.

\subsection{Previous Research}

Since Piaget (1952), many studies have shown that preschool children have mathematical skills. Geary (1994), Ginsburg (1989) showed that mathematical knowledge developed before school provided a basis for acquiring formal mathematical knowledge in schools.

There is also research on the relationship between the educator's ability and 
the children's mathematical ability. A survey of California's public and private preschool children's teachers revealed that preschoolers consider the environment of preschool to be more important than that of home when preparing for school mathematics (Starkey et al., 2004). Moreover, Kabita, et al., (2013) studied about the consciousness of preschool teachers for basic knowledge and mathematical activities. Furthermore, Lerkkanen, et al., (2012) examined the extent to which teaching practices observed in kindergarten classrooms predict children's interest in reading and mathematics. The results revealed that the children showed more interest in reading and mathematics, in classrooms in which the teachers placed greater emphasis on child-centered teaching practices than on teacher-directed practices. These researches indicated that the teachers' knowledge about mathematical education is important thing for the education of preschoolers.

About these increased attentions to early mathematics education, Chen et al. (2014) researched knowledge of what preschool teachers think about early math teaching and how confident they are in helping preschoolers learn math remains limited. The results they observed that level of teacher confidence varied with specific types of math knowledge and teaching abilities. And Sarama, et al., (2016) indicated about the importance of professional training to preschool teachers.

These studies provided the importance of knowledge and teacher education for mathematical education in preschool. And, regarding the development of mathematical ability, it was shown that the implementation in early childhood education was very important, and it was particularly significant that teachers in early childhood education had the ability to teach mathematical elements.

But the ability of preschool teachers to promote children's mathematical thinking isn't clarified and a scale to measure the ability isn't developed. Therefore, we tried to develop a scale for assessing preschool teachers' ability to develop the early development of children's mathematical thinking.

\subsection{Japanese Current Status}

There are three forms of early childhood education in Japan. The first form is a kindergarten as an educational institution. The second is a nursery school with a side as a childcare facility. The last form is a center for early childhood education and care with both sides as a child care facility and education institution. These are intended to fulfill the function as an early childhood education facility.

However, since the nursery school and a center for early childhood education and care have side as a child welfare institution, it is thought that education is less emphasized than at kindergarten. Childhood education in nursery schools and in a center for early childhood education and care is an urgent issue.

\subsection{Mathematics as a Basis of Foundation}

There is research on things that lead to "knowledge discovery and theorizing" on mathematics after elementary school in mathematics learning. Shunsuke et al. 
(2010) call "The rudimentary mathematics knowledge which is acquired through play activities" as "Basic Mathematics" (Gen-Sugaku). They regard that as "ability that become Basis of thinking logically (thinking) and Accurate cognition (cognition)" rather than just "basics of mathematics".

Basic Mathematics is composed of a fundamental matter regarding contents of mathematics and a way of thinking which works for recognizing the fundamental matter. The former includes comparison, correspondence, classification, split, counting together, ordering, amount, measurement, distance, construction, immutability/conservability, position, topology, shape, continuity, sequence, division into cases, organizing, connectivity. The other includes reasoning, analysis, synthesis, essence, relationship, abstraction and generalization, changing viewpoint, visualization, reversibility, transition law, and logical thinking. Acquiring these basis mathematics through play in early childhood education could be thought strongly correlated to mathematical recognition in mathematics education.

Basic Mathematics does not include some elements which we consider pupils should acquire(experience) at pre-school before learning mathematics at primary school such as counting, subitizing, making half, part-whole relationship and so on.

Therefore, in this research, Basic Mathematics and some added elements mentioned above are defined as Basis of Mathematics.

\section{Method}

\subsection{Participants}

Participants were teachers working in preschools $(n=157)$. All teachers were working in a center for early childhood education and care. 22 teachers had an experience to work in a kindergarten and a nursery school. 14 teachers had an experience to work in a kindergarten. 82 teachers had an experience to work in a nursery school. 35 teachers had only experience to work in a center for early childhood education and care.

\subsection{Survey Contents and Survey Period}

Table 1 shows the contents of questionnaire.

At first we decided to select following four items as what affect ability to promote children's mathematical thinking and as information we want to collect through questions; Experience of work as preschool teacher, Knowledge about Basis of mathematics, Consciousness toward children, play and childcare, and Practical ability of childcare such that creation of environmental constitution which leads to Basis of Mathematics, reading of the play and advising.

Regarding with each item, we set detailed questions tentatively with reference of Basis of Mathematics and asked principals of preschool about them. Based on their comments, we revised or delete questions and finally set 48 questions. 
Table 1. The contents of questionnaire.

The way of thinking about childcare

1_1 When doing childcare, I emphasize the daily life in order to protect the health and safety of children.

1_2 When doing childcare, I emphasize the educational aspect in order to realize "the state which you want children to grow up by the end of early childhood".

Understanding about Basis of Mathematics

2_1 I understand the contents of "Quantities and Figures" in the course of study for Kindergarten.

2_2 I understand the contents of "Sense of quantity and figures" in the course of study for Kindergarten.

2_3 I understand the written content about "mathematics" in the course of study for elementary schools.

2_4 I understand that there is an experience that become Basis of Mathematics in the play of children.

2_5 I understand the mathematics behind the play that become Basis of Mathematics.

2_6 I understand the development about children's cognition of number, quantity and shape.

Understanding about children, play and childcare

3_1 Interested in mathematics education in early childhood.

3_2 In early childhood education, the experience that forms Basis of Mathematics is important.

3_3 It is necessary to acquire Basis of Mathematics through the guided play.

3_4 It is necessary to acquire Basis of Mathematics through the non-guided play.

3_5 It is necessary to learn Basis of Mathematics not only through play but also from daily activities in the kindergarten.

3_6 In order for children to make a discovery Basis of Mathematics, they need the support of preschool teachers.

3_7 As Basis of Mathematics, it is important to have a way of thinking to grasp their daily life mathematically.

3_8 Mathematics terms may be taught according to the children's interests.

3_9 Mathematics tools may be given according to the children's interests.

Practice of childcare

4_1 I can make a childcare plan can be planned in consideration of the "link between play and mathematics".

4_2 I can set the environment to be a play that also leads to Basis of Mathematics.

4_3 Depending on the degree of recognition of the children, I can devise support so that it also leads to Basis of Mathematics.

$4 \_4$ In the play, can read the play of children that leads to Basis of Mathematics.

4_5 Depending on the children's play, can give advices that leads to Basis of Mathematics.

4_6 Depending on the children's play, I can create an environmental constitution that leads to Basis of Mathematics.

4_7 When doing childcare, I can read the play of children that leads to "collecting things of the same properties". (Matching)

$4 \_8$ When doing childcare, I can read the play of the children that leads to "dividing into groups focusing on differences". (Sorting)

4_9 When doing childcare, I can read the play of the children that leads to "comparing from the viewpoint of same, big, and small". (Comparing)

4_10 When doing childcare, I can read the play of the children that leads to "arranging in order of size". (Ordering) 


\section{Continued}

4_11 When doing childcare, I can read the play of the children that leads to "arranging based on the rules". (Patterning)

4_12 When doing childcare, I can read the play of children that leads to "counting". (Counting)

4_13 When doing childcare, I can read the play of the children that leads to "one-to-one correspondence". (One-to-one correspondence)

4_14 When doing childcare, I can read the play of the children that leads to "understanding the conservation of quantity". (Conservation of quantity)

4_15 When doing childcare, I can read the play of the children that leads to "understanding the part-whole relationship". (Part-whole relationship)

4_16 When doing childcare, can read the play of the children that leads to "momentarily grasping the number". (Subitizing)

4_17 When doing childcare, can read the play of the children that leads to "getting a sense of amount". (Amount)

4_18 When doing childcare, can read the play of children that leads to "combining basic shapes to create new shapes". (Basic shapes)

4_19 When doing childcare, can read the play of the children that leads to "understanding the position and relationship in space (up, down, front, back, left, right)". (Simple spatial concept)

$4 \_20$ When doing childcare, can read the play of the children that leads to "judgment of how many can be divided". (Measurement)

$4 \_21$ When doing childcare, can read the play of the children that leads to "counting together like two each, five each". (Counting together)

$4 \_22$ When doing childcare, can read the play of the children that leads to "making half". (Making half)

4_23 When doing childcare, I give advice which leads to "finding a point of similar". (Abstraction/generalization)

4_24 When I doing childcare, I advise "please think about if .... is....”. (Assumption)

4_25 When I doing childcare, I advise "please talk in order". (Logical thinking)

4_26 When I doing childcare, I advise "please speak the reason”. (Evidence)

$4 \_27$ When I doing childcare, I advise "please speak the most important thing". (Essence)

4_28 When I doing childcare, I advise "please speak based on relationship". (Relationship)

4_29 When I doing childcare, I give advice which leads to "visualizing what I thought". (Visualization)

4_30 When I doing childcare, I give advice which leads to "reflecting on what I have done". (Reflection)

\subsection{Date Analysis}

The structures of the ability of preschool teachers to promote children's mathematical thinking were analyzed using factor analysis. Then, an analysis of variance (ANOVA), multiple comparisons, correlation analysis, and multiple regression analysis were conducted. SPSS 23.0 was used for data analysis.

\section{Results}

\subsection{Date of Participants}

Table 2 shows the data about the consciousness of mathematics for participants. 
Table 2. The average values and standard deviation of each item.

\begin{tabular}{cccc}
\hline & good at mathematics & not good at mathematics & n \\
\hline consciousness of mathematics & 22 & 131 & 153 \\
& license & non license & \\
$\begin{array}{c}\text { the license of education in } \\
\text { elementary school }\end{array}$ & 30 & 122 & 152 \\
& nursery school & non & \\
experiences of working in nursery school & 49 & 104 & 153 \\
experiences of studying mathematics & 75 & extension & \\
& kindergarten & 78 & 153 \\
experiences of working in kindergarten & 117 & non & 153 \\
\hline
\end{tabular}

These indicate that teachers who are good or not good at mathematics, have or don't have a license for elementary school, have or don't have an experience of working nursery school, have or don't have an experience of learning extension mathematics, and have or don't have an experience of working a kindergarten.

\subsection{Factor Analysis}

First, average values and standard deviation for the 47 items of the ability of preschool teachers to promote children's mathematical thinking were determined. In order to identify the ceiling and floor effects for each item, the average value \pm standard deviation of the range from the minimum to the maximum value was determined. The average values and standard deviation of each item are shown in Table 3.

A ceiling effect and a floor effect were not observed, and as all items were considered important to exploratory factor analysis in this study, they were not excluded from the analysis.

An analysis using the re-likehood method with Promax rotation was performed on the 47 items with an insufficient factor-loading (0.40) were excluded from the analysis.

The final factor patterns and factor correlations are displayed in Table 4.

Seven factors were extracted as a result of the factor analysis.

The first factor was named the "The ability to read the play that leads to Basis of Mathematics (extensions)". The second factor was named the "Advice for leading to Basis of Mathematics". The third factor was named the "The way of thinking to Basis of Mathematics". The fourth factor was named the "Practice of childcare leading to Basis of Mathematics". The fifth factor was named the "The ability to read the play that leads to Basis of Mathematics (basics)". The sixth factor was named the "Understanding Basis of Mathematics". The seventh factor was named the "The way of thinking to early education".

In addition, the $a$ coefficients of items constituting each factor were calculated 
Table 3. The average values and standard deviation of each item.

\begin{tabular}{|c|c|c|c|c|c|c|}
\hline number of questionnaires & $\mathrm{n}$ & Min & $\operatorname{Max}$ & $\mathrm{AV}$ & \pm & SD \\
\hline $1 \_1$ & 153 & 4 & 7 & 6.07 & \pm & 0.77 \\
\hline $1 \_2$ & 153 & 3 & 7 & 5.58 & \pm & 0.83 \\
\hline $2 \_1$ & 153 & 1 & 7 & 4.20 & \pm & 1.12 \\
\hline $2 \_2$ & 153 & 1 & 7 & 4.05 & \pm & 1.17 \\
\hline $2 \_3$ & 150 & 1 & 7 & 3.12 & \pm & 1.42 \\
\hline $2 \_4$ & 152 & 2 & 7 & 5.02 & \pm & 1.05 \\
\hline $2 \_5$ & 152 & 1 & 7 & 4.05 & \pm & 1.15 \\
\hline $2 \_6$ & 153 & 1 & 7 & 4.56 & \pm & 1.04 \\
\hline $3 \_1$ & 153 & 2 & 7 & 4.71 & \pm & 1.09 \\
\hline $3 \_2$ & 153 & 2 & 7 & 5.48 & \pm & 0.97 \\
\hline $3 \_3$ & 153 & 2 & 7 & 4.71 & \pm & 1.07 \\
\hline 3_4 & 153 & 2 & 7 & 5.11 & \pm & 0.97 \\
\hline 3_5 & 153 & 2 & 7 & 5.12 & \pm & 0.91 \\
\hline $3 \_6$ & 153 & 2 & 7 & 5.31 & \pm & 1.02 \\
\hline 3_7 & 151 & 2 & 7 & 4.64 & \pm & 1.04 \\
\hline 3_8 & 153 & 3 & 7 & 4.89 & \pm & 1.00 \\
\hline 3_9 & 153 & 3 & 7 & 4.90 & \pm & 0.92 \\
\hline $4 \_1$ & 153 & 1 & 6 & 3.92 & \pm & 1.01 \\
\hline $4 \_2$ & 153 & 1 & 7 & 4.29 & \pm & 0.97 \\
\hline $4 \_3$ & 153 & 2 & 7 & 4.39 & \pm & 0.91 \\
\hline $4 \_4$ & 153 & 2 & 7 & 4.41 & \pm & 0.92 \\
\hline 4_5 & 153 & 2 & 7 & 4.62 & \pm & 0.93 \\
\hline $4 \_6$ & 153 & 2 & 7 & 4.32 & \pm & 0.95 \\
\hline 4_7 & 153 & 1 & 7 & 4.56 & \pm & 0.89 \\
\hline $4 \_8$ & 152 & 2 & 7 & 4.70 & \pm & 0.82 \\
\hline 4_9 & 153 & 2 & 7 & 5.08 & \pm & 0.82 \\
\hline 4_10 & 153 & 2 & 7 & 4.99 & \pm & 0.87 \\
\hline 4_11 & 153 & 2 & 7 & 4.72 & \pm & 0.93 \\
\hline $4 \_12$ & 153 & 3 & 7 & 5.17 & \pm & 0.90 \\
\hline 4_13 & 153 & 1 & 7 & 4.25 & \pm & 0.97 \\
\hline 4_14 & 153 & 1 & 7 & 3.93 & \pm & 0.94 \\
\hline 4_15 & 153 & 1 & 7 & 4.07 & \pm & 0.94 \\
\hline $4 \_16$ & 153 & 1 & 7 & 4.33 & \pm & 1.01 \\
\hline 4_17 & 153 & 2 & 7 & 4.52 & \pm & 0.92 \\
\hline 4_18 & 153 & 2 & 7 & 4.78 & \pm & 0.91 \\
\hline 4_19 & 153 & 1 & 7 & 4.61 & \pm & 1.01 \\
\hline $4 \_20$ & 153 & 1 & 7 & 4.13 & \pm & 1.00 \\
\hline $4 \_21$ & 152 & 1 & 7 & 4.43 & \pm & 1.01 \\
\hline $4 \_22$ & 152 & 2 & 7 & 4.53 & \pm & 0.96 \\
\hline
\end{tabular}




\section{Continued}

\begin{tabular}{lllllll}
\hline $4 \_23$ & 153 & 1 & 7 & $4.94 \pm 0.85$ \\
$4 \_24$ & 153 & 1 & 7 & $4.74 \pm 1.01$ \\
$4 \_25$ & 153 & 3 & 7 & $5.17 \pm 0.81$ \\
$4 \_26$ & 153 & 3 & 7 & $5.49 \pm 0.81$ \\
$4 \_27$ & 153 & 3 & 7 & $5.44 \pm 0.85$ \\
$4 \_28$ & 153 & 3 & 7 & $4.86 \pm 0.91$ \\
$4 \_29$ & 153 & 1 & 7 & $4.71 \pm 1.04$ \\
$4 \_30$ & 153 & 3 & 7 & $5.30 \pm 0.89$ \\
\hline
\end{tabular}

Table 4. The final factor patterns and factor correlations.

\begin{tabular}{|c|c|c|c|c|c|c|c|}
\hline & 1 & 2 & 3 & 4 & 5 & 6 & 7 \\
\hline 4_14 & 0.957 & 0.007 & -0.095 & -0.022 & -0.196 & 0.02 & 0.065 \\
\hline 4_15 & 0.902 & -0.053 & -0.03 & 0.018 & -0.065 & 0.027 & -0.06 \\
\hline 4_13 & 0.771 & 0.008 & -0.029 & 0.042 & 0.042 & 0.013 & -0.05 \\
\hline $4 \_20$ & 0.735 & 0.033 & -0.029 & 0.045 & 0 & 0.021 & 0.018 \\
\hline 4_17 & 0.715 & 0.12 & 0.106 & -0.121 & 0.179 & -0.067 & -0.112 \\
\hline $4 \_16$ & 0.659 & -0.016 & 0.133 & -0.03 & 0.185 & -0.058 & -0.104 \\
\hline $4 \_22$ & 0.527 & 0.055 & 0.093 & 0.147 & 0.097 & -0.064 & 0.018 \\
\hline 4_19 & 0.506 & 0.035 & 0.026 & 0.222 & 0.142 & -0.043 & -0.063 \\
\hline $4 \_21$ & 0.493 & 0.002 & 0.166 & 0.09 & 0.05 & 0.018 & 0.11 \\
\hline $4 \_26$ & -0.139 & 0.99 & 0.03 & -0.13 & 0.124 & -0.019 & -0.051 \\
\hline $4 \_27$ & -0.071 & 0.888 & 0.005 & -0.018 & -0.006 & -0.035 & 0.089 \\
\hline $4 \_25$ & 0.207 & 0.815 & 0.068 & -0.141 & -0.071 & -0.07 & -0.044 \\
\hline $4 \_28$ & 0.142 & 0.796 & -0.11 & 0.087 & -0.143 & -0.013 & 0.091 \\
\hline $4 \_30$ & -0.087 & 0.643 & -0.019 & 0.06 & 0.108 & -0.061 & 0.058 \\
\hline $4 \_24$ & 0.196 & 0.525 & -0.059 & -0.031 & 0.012 & 0.105 & -0.006 \\
\hline $1-2$ & 0.036 & 0.499 & 0.031 & 0.142 & -0.178 & 0.022 & 0 \\
\hline $4 \_29$ & 0.064 & 0.497 & -0.16 & 0.103 & -0.006 & 0.16 & -0.022 \\
\hline $3-5$ & -0.114 & 0.006 & 0.811 & 0.215 & -0.047 & -0.104 & -0.039 \\
\hline $3-6$ & -0.098 & 0.093 & 0.78 & -0.14 & 0.013 & -0.025 & 0.086 \\
\hline $3-4$ & -0.099 & 0.034 & 0.766 & 0.172 & -0.01 & -0.099 & 0.037 \\
\hline $3-2$ & 0.052 & -0.058 & 0.745 & 0.033 & -0.022 & 0.004 & -0.011 \\
\hline $3-3$ & 0.176 & -0.112 & 0.741 & -0.279 & -0.004 & 0.091 & 0.033 \\
\hline $3-7$ & 0.298 & -0.116 & 0.584 & -0.052 & -0.2 & 0.119 & 0.148 \\
\hline $2-4$ & -0.151 & 0.101 & 0.462 & 0.257 & 0.044 & 0.205 & -0.149 \\
\hline $4 \_2$ & 0.158 & -0.093 & -0.105 & 0.938 & -0.11 & 0.01 & 0.029 \\
\hline 4_6 & 0.026 & -0.004 & -0.054 & 0.868 & 0.059 & -0.022 & -0.009 \\
\hline $4 \_3$ & 0.164 & -0.049 & 0.075 & 0.797 & -0.068 & -0.086 & 0.049 \\
\hline
\end{tabular}




\begin{tabular}{|c|c|c|c|c|c|c|c|}
\hline \multicolumn{8}{|c|}{ Continued } \\
\hline $4 \_5$ & -0.116 & 0.048 & 0.137 & 0.691 & 0.195 & -0.015 & -0.03 \\
\hline 4_4 & 0.029 & 0.031 & 0.066 & 0.648 & 0.166 & -0.033 & -0.042 \\
\hline $4 \_1$ & 0.203 & -0.042 & -0.024 & 0.576 & -0.085 & 0.203 & 0.013 \\
\hline $4 \_7$ & 0.302 & -0.022 & -0.081 & 0.452 & 0.061 & -0.011 & 0.079 \\
\hline $4 \_10$ & 0.006 & -0.089 & -0.119 & 0.047 & 0.939 & 0.101 & 0.064 \\
\hline 4_12 & 0.1 & 0.041 & 0.065 & -0.021 & 0.802 & 0.01 & -0.116 \\
\hline 4_9 & -0.01 & 0.033 & -0.094 & 0.061 & 0.761 & 0.058 & 0.123 \\
\hline 4_18 & 0.272 & 0.108 & 0.046 & -0.044 & 0.505 & -0.039 & 0.079 \\
\hline $4 \_8$ & 0.313 & 0.01 & -0.056 & 0.154 & 0.458 & 0.015 & 0.003 \\
\hline $2-1$ & -0.072 & 0.042 & 0.069 & 0.003 & 0.038 & 0.932 & -0.101 \\
\hline $2-2$ & 0.036 & 0.033 & 0.064 & 0.11 & -0.023 & 0.76 & 0.022 \\
\hline $2-3$ & 0.02 & -0.142 & -0.104 & -0.086 & 0.179 & 0.49 & 0.167 \\
\hline $3-8$ & -0.05 & 0.02 & 0.105 & -0.095 & 0.148 & 0.093 & 0.82 \\
\hline $3-9$ & -0.046 & 0.092 & 0.035 & 0.119 & -0.027 & -0.023 & 0.783 \\
\hline
\end{tabular}

to examine the internal consistency of the factors, which indicated the following coefficients: The ability to read the play that leads to Basis of Mathematics (extensions) factor ( $\alpha=0.919$ ), Advice for leading to Basis of Mathematics factor ( $\alpha$ $=0.874)$, The way of thinking to Basis of Mathematics factor $(\alpha=0.880)$, Practice of childcare leading to Basis of Mathematics factor $(\alpha=0.921)$, The ability to read the play that leads to Basis of Mathematics (basics) factor $(\alpha=0.915)$, Understanding Basis of Mathematics factor $(\alpha=0.746)$, The way of thinking to early education factor $(\alpha=0.84)$. Moreover a correlation analysis between the factor scores is displayed in Table 5. Exclude four items of 48 items, there was a significant correlation between the factor scores.

\subsection{Differences Based on Experiences by Multiple Comparisons}

The average value and the standard deviation of the factor scores are shown in Table 6.

A one-way ANOVA was conducted by regarding the experience as a between-subject factor. A significant main effect was indicated for the ability to read the play that leads to Basis of mathematics (extensions), the advice for leading to Basis of Mathematics, and the practice of childcare leading to Basis of Mathematics.

The results of multiple comparisons indicated that in the ability to read the play that leads to Basis of mathematics (extensions), and the practice of childcare leading to Basis of Mathematics, average value of teachers who had experiences of kindergarten and nursery school were significantly higher than that of teachers who had an experience of a nursery school or teachers who had only experience of a center for early childhood education and care.

Moreover, the results of multiple comparisons indicated that in the advice for 
Table 5. Correlation analysis between the factor scores.

\begin{tabular}{|c|c|c|c|c|c|c|c|c|}
\hline & & 1 & 2 & 3 & 4 & 5 & 6 & 7 \\
\hline 1 & $\begin{array}{l}\text { The ability to read the play that leads to Basis of Mathematics } \\
\text { (extensions) }\end{array}$ & & $0.526^{* *}$ & $0.359^{* *}$ & $0.728^{* *}$ & $0.718^{* *}$ & $0.457^{* *}$ & 0.158 \\
\hline 2 & Advice for leading to Basis of Mathematics & $0.526^{* *}$ & & $0.306^{* *}$ & $0.474^{\star *}$ & $0.534^{\star *}$ & $0.292 * *$ & $0.23 * *$ \\
\hline 3 & The way of thinking to grasp Basis of Mathematics & $0.359^{\star *}$ & $0.306^{\star \star}$ & & $0.443^{\star *}$ & $0.282^{\star \star}$ & $0.346^{* *}$ & $0.279^{\star *}$ \\
\hline 4 & Practice of childcare leading to Basis of Mathematics & $0.728^{\star *}$ & $0.474^{\star *}$ & $0.443^{* *}$ & & $0.675^{\star *}$ & $0.544^{* *}$ & $0.165^{\star}$ \\
\hline 5 & $\begin{array}{l}\text { The ability to read the play that leads to Basis of Mathematics } \\
\text { (basics) }\end{array}$ & $0.718^{* *}$ & $0.534^{* *}$ & $0.282^{\star *}$ & $0.675^{* *}$ & & $0.388^{* *}$ & $0.274^{* *}$ \\
\hline 6 & Understanding Basis of Mathematics & $0.457^{* *}$ & $0.292 * *$ & $0.346^{* *}$ & $0.544^{\star *}$ & $0.388^{* *}$ & & 0.14 \\
\hline 7 & The way of thinking to early education & 0.158 & $0.23^{\star *}$ & $0.279 * *$ & $0.165 *$ & $0.274^{* *}$ & 0.14 & \\
\hline
\end{tabular}

${ }^{\star} p<0.05,{ }^{* *} p<0.01$.

Table 6. The average value and the standard deviation of the factor scores.

\begin{tabular}{|c|c|c|c|c|}
\hline & $\begin{array}{l}\text { 1. kindergarten \& } \\
\text { nursery school }\end{array}$ & 2. kindergarten & $\begin{array}{l}\text { 3. nursery } \\
\text { school }\end{array}$ & 4. non \\
\hline & $\mathrm{AV} \pm \mathrm{SD}$ & $\mathrm{AV} \pm \mathrm{SD}$ & $\mathrm{AV} \pm \mathrm{SD}$ & $\mathrm{AV} \pm \mathrm{SD}$ \\
\hline $\begin{array}{l}\text { The ability to read the play that leads to Basis of Mathematics } \\
\text { (extensions) }\end{array}$ & $4.82 \pm 0.92$ & $4.34 \pm 0.60$ & $4.25 \pm 0.79$ & $4.08 \pm 0.591>3,4$ \\
\hline Advice for leading to Basis of Mathematics & $5.57 \pm 0.70$ & $5.31 \pm 0.56$ & $5.05 \pm 0.65$ & $5.15 \pm 0.56 \quad 1>3$ \\
\hline The way of thinking to grasp Basis of Mathematics & $5.35 \pm 0.88$ & $5.29 \pm 0.77$ & $4.92 \pm 0.67$ & $5.03 \pm 0.85$ \\
\hline Practice of childcare leading to Basis of Mathematics & $4.91 \pm 0.91$ & $4.54 \pm 0.61$ & $4.25 \pm 0.75$ & $4.19 \pm 0.681>3,4$ \\
\hline The ability to read the play that leads to Basis of Mathematics (basics) & $5.14 \pm 0.97$ & $5.09 \pm 0.36$ & $4.90 \pm 0.76$ & $4.83 \pm 0.69$ \\
\hline Understanding Basis of Mathematics & $4.18 \pm 1.33$ & $3.74 \pm 1.01$ & $3.71 \pm 0.93$ & $3.67 \pm 0.93$ \\
\hline The way of thinking to early education & $4.93 \pm 1.07$ & $4.71 \pm 0.89$ & $4.90 \pm 0.83$ & $4.93 \pm 0.91$ \\
\hline
\end{tabular}

${ }^{\star} p<0.05,{ }^{* *} p<0.01$.

leading to Basis of Mathematics, average value of teachers who had experiences of kindergarten and nursery school were significantly higher than that of teachers who have an experience of a nursery school.

\subsection{Differences Based on Experiences by t-Test}

The t-test was conducted for each factor by the consciousness of mathematics. Table 7 shows the results of independent $t$-test between the two groups by the consciousness of mathematics. The results of independent t-test showed that there was no significant difference between the two groups by the consciousness of mathematics at the 0.05 level of significance on each factor. However, in the scores of all factors, average value of teachers who were good at mathematics were higher than that of teachers who were not good at mathematics.

The $t$-test was conducted for each factor by license of education in elementary school. Table 8 shows the results of independent $t$-test between the two groups by the license of education in elementary school. 
Table 7. Results of independent t-test between the two groups by the consciousness of mathematics.

\begin{tabular}{|c|c|c|c|}
\hline & $\begin{array}{c}\text { good at } \\
\text { mathematics }\end{array}$ & $\begin{array}{l}\text { not good at } \\
\text { mathematics }\end{array}$ & $\mathrm{t}$ \\
\hline $\begin{array}{l}\text { The ability to read the play that leads to Basis of } \\
\text { Mathematics (extensions) }\end{array}$ & $4.53 \pm 0.63$ & $4.26 \pm 0.80$ & 1.51 \\
\hline Advice for leading to Basis of Mathematics & $5.18 \pm 0.54$ & $5.17 \pm 0.67$ & 0.08 \\
\hline The way of thinking to grasp Basis of Mathematics & $5.20 \pm 0.72$ & $5.01 \pm 0.77$ & 1.08 \\
\hline Practice of childcare leading to Basis of Mathematics & $4.55 \pm 0.64$ & $4.33 \pm 0.80$ & 1.25 \\
\hline $\begin{array}{l}\text { The ability to read the play that leads to Basis of } \\
\text { Mathematics (basics) }\end{array}$ & $5.07 \pm 0.73$ & $4.91 \pm 0.76$ & 0.91 \\
\hline Understanding Basis of Mathematics & $4.00 \pm 0.79$ & $3.73 \pm 1.04$ & 1.13 \\
\hline The way of thinking to early education & $5.00 \pm 0.90$ & $4.88 \pm 0.89$ & 0.60 \\
\hline
\end{tabular}

${ }^{*} p<0.01,{ }^{* *} p<0.01$.

Table 8. Results of independent t-test between the two groups by the license of education in elementary school.

\begin{tabular}{|c|c|c|c|}
\hline & license & non license & $\mathrm{t}$ \\
\hline $\begin{array}{l}\text { The ability to read the play that leads to Basis of } \\
\text { Mathematics (extensions) }\end{array}$ & $4.34 \pm 0.91$ & $4.29 \pm 0.75$ & 0.29 \\
\hline Advice for leading to Basis of Mathematics & $5.10 \pm 0.59$ & $5.20 \pm 0.66$ & -0.75 \\
\hline The way of thinking to grasp Basis of Mathematics & $5.04 \pm 0.75$ & $5.05 \pm 0.77$ & -0.11 \\
\hline Practice of childcare leading to Basis of Mathematics & $4.45 \pm 0.89$ & $4.34 \pm 0.76$ & 0.68 \\
\hline $\begin{array}{l}\text { The ability to read the play that leads to Basis of } \\
\text { Mathematics (basics) }\end{array}$ & $5.07 \pm 0.73$ & $4.91 \pm 0.76$ & 1.06 \\
\hline Understanding Basis of Mathematics & $4.15 \pm 0.95$ & $3.68 \pm 1.01$ & 2.31 \\
\hline The way of thinking to early education & $4.90 \pm 0.87$ & $4.90 \pm 0.89$ & -0.01 \\
\hline
\end{tabular}

${ }^{*} p<0.01,{ }^{* *} p<0.01$.

The results of independent $\mathrm{t}$-test showed that there was no significant difference between the two groups by license of education in elementary school at the 0.05 level of significance on each factor. However, in the scores of 4 factors, teachers who had the license were higher than teachers who didn't have the license.

The t-test was conducted for each factor by experiences of working in nursery school. Table 9 shows the results of independent $\mathrm{t}$-test between the two groups by experiences of working in nursery school.

The results of independent t-test showed that there was no significant difference between the two groups by experiences of working in nursery school at the 0.05 level of significance on each factor.

Further, in the scores of 5 factors, average value of teachers who had an experience of working in nursery school were lower than that of teachers who had non experience of working in nursery school. 
Table 9. Results of independent t-test between the two groups by experiences of working in nursery school.

\begin{tabular}{|c|c|c|c|}
\hline & nursery school & non & $\mathrm{t}$ \\
\hline $\begin{array}{l}\text { The ability to read the play that leads to Basis of Mathematics } \\
\text { (extensions) }\end{array}$ & $4.16 \pm 0.60$ & $4.37 \pm 0.85$ & -1.60 \\
\hline Advice for leading to Basis of Mathematics & $5.19 \pm 0.56$ & $5.16 \pm 0.69$ & 0.27 \\
\hline The way of thinking to grasp Basis of Mathematics & $5.11 \pm 0.83$ & $5.01 \pm 0.74$ & 0.74 \\
\hline Practice of childcare leading to Basis of Mathematics & $4.29 \pm 0.67$ & $4.39 \pm 0.83$ & -0.71 \\
\hline $\begin{array}{l}\text { The ability to read the play that leads to Basis of Mathematics } \\
\text { (basics) }\end{array}$ & $4.91 \pm 0.62$ & $4.95 \pm 0.81$ & -0.35 \\
\hline Understanding Basis of Mathematics & $3.69 \pm 0.94$ & $3.81 \pm 1.04$ & -0.70 \\
\hline The way of thinking to early education & $4.87 \pm 0.90$ & $4.91 \pm 0.88$ & -0.27 \\
\hline
\end{tabular}

The t-test was conducted for each factor by experiences of studying mathematics (basic or extension) in a high school. Table 10 shows the results of independent $\mathrm{t}$-test between the two groups by experiences of studying mathematics (basic or extension) in a high school.

The results of independent $t$-test showed that there was no significant difference between the two groups by experiences of studying mathematics in a high school at the 0.05 level of significance on each factor. However, in the scores of all factors, teachers who had an experience of studying mathematics (extension) were higher than teachers who didn't have an experience of studying mathematics (basic).

The $\mathrm{t}$-test was conducted for each factor by experiences of working in kindergarten. Table 11 shows the results of independent t-test between the two groups by experiences of working in kindergarten.

The results of independent $t$-test showed that there were a significant difference between the two groups by experience of working in kindergarten at the 0.05 level of significance on the ability to read the play that leads to Basis of Mathematics (extensions) $(\mathrm{t}=-2.974, \mathrm{df}=151, p=0.003)$, advice for leading to $\mathrm{Ba}$ sis of Mathematics $(\mathrm{t}=-3.233, \mathrm{df}=151, p=0.002)$, and practice of childcare leading to Basis of Mathematics $(\mathrm{t}=-3.749, \mathrm{df}=151, p=0.000)$. Average value of teachers who have an experience of working in kindergarten were higher than that of others.

\section{Conclusion}

\subsection{The Scale of Ability of Preschool Teachers to Promote Children's Mathematical Thinking}

The scale of ability of preschool teachers to promote children's mathematical thinking was developed through the quantitative evaluation of the ability about teaching mathematical thinking in the education of early childhood education.

As a result, seven factors were extracted as subscales: "The ability to read the play that leads to Basis of Mathematics (extensions)", "Advice for leading to Basis 
Table 10. Results of independent t-test between the two groups by experiences of studying mathematics (basic or extension) in a high school.

\begin{tabular}{lcccc}
\hline & basic & extension & $\mathrm{t}$ \\
\hline $\begin{array}{l}\text { The ability to read the play that leads to Basis of } \\
\text { Mathematics (extensions) }\end{array}$ & $0.85 \pm 0.10$ & $0.70 \pm 0.08$ & -1.59 \\
$\begin{array}{l}\text { Advice for leading to Basis of Mathematics } \\
\text { The way of thinking to grasp Basis of Mathematics }\end{array}$ & $0.67 \pm 0.08$ & $0.63 \pm 0.07$ & -1.06 \\
Practice of childcare leading to Basis of Mathematics & $0.85 \pm 0.10$ & $0.66 \pm 0.07$ & -1.70 \\
$\begin{array}{l}\text { The ability to read the play that leads to Basis of } \\
\text { Mathematics (basics) }\end{array}$ & $0.88 \pm 0.10$ & $0.67 \pm 0.08$ & -1.57 \\
Understanding Basis of Mathematics & $0.85 \pm 0.10$ & $0.65 \pm 0.07$ & -1.46 \\
The way of thinking to early education & $1.11 \pm 0.13$ & $0.88 \pm 0.10$ & -1.66 \\
\hline
\end{tabular}

${ }^{\star} p<0.01,{ }^{* *} p<0.01$.

Table 11. Results of independent $t$-test between the two groups by experiences of working in kindergarten.

\begin{tabular}{|c|c|c|c|c|}
\hline & kindergarten & non & $\mathrm{t}$ & \\
\hline $\begin{array}{l}\text { The ability to read the play that leads to Basis of } \\
\text { Mathematics (extensions) }\end{array}$ & $4.20 \pm 0.74$ & $4.63 \pm 0.83$ & -2.97 & * \\
\hline Advice for leading to Basis of Mathematics & $5.08 \pm 0.63$ & $5.47 \pm 0.66$ & -3.23 & * \\
\hline The way of thinking to grasp Basis of Mathematics & $4.95 \pm 0.73$ & $5.33 \pm 0.83$ & -2.59 & * \\
\hline Practice of childcare leading to Basis of Mathematics & $4.23 \pm 0.73$ & $4.77 \pm 0.82$ & -3.75 & $* *$ \\
\hline $\begin{array}{l}\text { The ability to read the play that leads to Basis of } \\
\text { Mathematics (basics) }\end{array}$ & $4.88 \pm 0.74$ & $5.12 \pm 0.79$ & -1.64 & \\
\hline Understanding Basis of Mathematics & $3.70 \pm 0.93$ & $4.01 \pm 1.22$ & -1.64 & \\
\hline The way of thinking to early education & $4.91 \pm 0.85$ & $4.85 \pm 1.00$ & 0.372 & \\
\hline
\end{tabular}

${ }^{*} p<0.01,{ }^{* *} p<0.01$.

of Mathematics", "The way of thinking Basis of Mathematics", "Practice of childcare leading to Basis of Mathematics", "The ability to read the play that leads to Basis of Mathematics (basics)", "Understanding Basis of Mathematics", and "The way of thinking to early education".

Then, an analysis of ability to promote children's mathematical thinking in preschool teachers was conducted on several viewpoints.

\subsection{Correlation between the Teacher's Ability to Promote Children's Mathematical Thinking and the Experience of Working}

The results indicated no significant difference in the scores about good or not good at mathematics, have or don't have a license for elementary school, have or don't have an experience of working nursery school, and have or don't have an experience of learning extensional mathematics.

But the results indicated a significant difference in the scores about having or 
not having an experience of working a kindergarten.

Special effort to understand the relationship between children's play and mathematical thinking is necessary for preschool teachers who had no experience of working in kindergarten. These findings indicated the important matter of teachers education.

This scale is useful for finding the important matter of teachers education.

\subsection{Summary and Future Challenges}

In this study, a scale was developed to measure the ability of preschool teachers to promote children's mathematical thinking. By analyzing the ability of preschool teachers to promote children's mathematical thinking, we could understand the current state of preschool teachers in Japan. Therefore, we are able to state that the ability of preschool teachers to promote children's mathematical thinking was not at enough level. In addition, it was shown that the ability to promote children's mathematical thinking of preschool teachers who have no experience of working kindergarten was lower than that of teachers who have experience of working kindergarten.

Evaluating the ability of preschool teachers to promote children's mathematical thinking by the scales is important for revealing current situation of preschool education and finding suggestion to teacher education.

However, this research is a survey of preschool teachers in one time, for this reason, the following three issues will be addressed in the future. The first is to conduct the same questionnaire in other preschool. This enhances the reliability of the analysis in this study.

The second is that it is necessary to conduct longitudinal surveys on the same teachers. This makes it possible to analyze the influence on the ability of preschool teachers to promote children's mathematical thinking due to conducting in teachers education.

It will be possible to derive the relationship between teachers education and ability of teachers in more detail. The third is to provide in detail the contents of mathematics education in preschool.

Thus, unresolved problems remain in this research. However, developing the scale to assess the ability of preschool teachers to promote children's mathematical thinking is significant and by using this scale we become able to grasp the actual situation of the preschool teachers and the important matter of teachers education. Furthermore, it can give a new viewpoint of assessing ability of mathematic thinking and understanding preschool teacher's situation and each preschool's situation.

\section{Conflicts of Interest}

The authors declare no conflicts of interest regarding the publication of this paper.

\section{References}

Bereiter, C., \& Engelman, S. (1966). Teaching Disadvantaged Children in the Preschool. 
Englewood Cliffs, NJ: Prentice-Hall.

Chen, J. Q., Jennifer, M., Margaret, A., \& Christine, L. (2014). A Survey Study of Early Childhood Teachers' Beliefs and Confidence about Teaching Early Math. Early Childhood Education Journal, 42, 367-377. https://doi.org/10.1007/s10643-013-0619-0

Geary, D. C. (1994). Children's Mathematical Development. Washington DC: American Psychological Association.

Ginsburg, H. P. (1989). Children’s Arithmetic (2nd ed.). Austin, TX: Pro-Ed.

Kabita, B., Marea, T., \& Grace, S. (2013). Teaching of Science and Mathematics in Pre-Schools of Botswana: The Existing Practices. Creative Education, 4, 43-51. https://doi.org/10.4236/ce.2013.47A1006

Lerkkanen, M. K., Kiuru, N., Pakarinen, E., Viljaranta, J., Poikkeus, A.-M., Rasku-Puttonen, H., Siekkinen, M., \& Nurmi, J. E. (2012). The Role of Teaching Practices in the Development of Children's Interest in Reading and Mathematics in Kindergarten. Contemporary Educational Psychology, 37, 266-279. https://doi.org/10.1016/j.cedpsych.2011.03.004

Piaget, J. (1952). The Child's Conception of Number. London: Routledge \& Kegan Paul Ltd.

Sarama, J., Clements, D. H., Wolfe, C. B., \& Spitler, M. E. (2016). Professional Development in Early Mathematics: Effects of an Intervention Based on Learning Trajectories on Teacher's Practice. Nordic Studies in Mathematics Education, 21, 29-55.

Shunsuke, F., Yoko, S., Atsushi, S., Yumi, F., Keiko, N., Yoshimi, U., Chizu, N., \& Kyousuke, A. (2010). A Study on Curriculum Development for the Children's Basic Mathematical Cognition by Connecting "Number, Quantity and Figure" in Kindergarten Content Areas with "Mathematics" in Elementary School Subjects. Konan Women's University Researches Studies in Human Sciences, 46, 83-94.

Starkey, P., Klein, A., \& Wakeley, A. (2004). Enhancing Young Children's Mathematical Knowledge through a Pre-Kindergarten Mathematics Intervention. Early Childhood Research Quarterly, 19, 99-120. https://doi.org/10.1016/j.ecresq.2004.01.002 